EVS26

Los Angeles, California, May 6-9, 2012

\title{
Impact of passenger thermal comfort and electric devices temperature on range: a system simulation approach
}

\author{
Lionel Broglia, Gabriel Autefage, Matthieu Ponchant \\ LMS Imagine, 84 quai Charles de Gaulle, Lyon, 69006, France, lionel.broglia@lmsintl.com
}

\begin{abstract}
The range of Electric Vehicles is highly influenced by the electric power consumed by auxiliaries, a huge part of this power being used for cabin heat-up and cool-down operations in order to ensure an acceptable level of thermal comfort for the passengers. Driving range decreases with low temperatures in particular because cabin heating system requires an important amount of electric power. Range also decreases with high ambient temperatures because of the air conditioning system with electrically-driven compressor. At the same time, batteries and electric motors operates at their maximal efficiency in a certain range of temperature. The reduced EV driving range under real life operating cycles, which can be a barrier against market penetration, is an issue for further development in the future towards sophisticated cabin heating and cooling systems, as well as battery warmer.

The aim of this paper is to highlight the benefits of a system simulation approach, based on LMS Imagine.Lab AMESim, in order to estimate the impact of various technologies of cabin heating and cooling on both the cabin temperature and the driving range. In this paper, a battery electric vehicle including a cabin heating with PTC device and a R134a refrigerant loop is simulated under various ambient temperatures on a given driving cycle with the same required cabin temperature target. Simulation outputs include the cabin temperature evolution, the battery state of charge and as a consequence the driving range.
\end{abstract}

Keywords: Model Based System Engineering, Energy Management, Thermal Comfort, Battery Losses

\section{Introduction}

The aim of this paper is to highlight the benefits of a system simulation approach in order to estimate the impact of the ambient temperature on the energy consumed on a driving cycle, this energy consumption being variable with time due to cabin cooling or heating and due to losses in the battery and the electric machine.
The vehicle considered is a battery electrical vehicle including both a cabin heating with PTC device and a R134a refrigerant loop. The vehicle follows a SFTP-US06 driving cycle under various ambient temperatures with cabin temperature request of $20^{\circ} \mathrm{C}$. 


\section{Simulation approach}

Due to the increasing number of interactions between the vehicle subsystems (mechanical, thermal, electrical and controls), design analyses at component level proved to be insufficient. Today, automotive OEM design departments define targets for subsystems in early stage by taking into account individual vehicle attributes. However, several attributes have an impact on different subsystems, indicating the need for a multi-attribute target setting using an appropriate vehicle synthesis approach.

The interest of Model Based System Engineering using a multi-level and multi-domain system simulation approach for transient and vehicle synthesis analyses has been proven in the case of conventional vehicle [1] [2] and hybrid vehicle [3] [4]. The attributes considered by the approach are: vehicle performance, energy consumption, drivability and thermal comfort.

In the case of a battery electric vehicle considered in this paper, the following subsystems need to be represented:

- battery and its cooling/warming device

- electric machine

- the driveline and the vehicle

- the cabin air-conditioning system

- the cabin heating system

- the cabin and its thermal exchanges

LMS Imagine.Lab AMESim sketch in Figure 1 below shows the EV different subsystems representation.

Each of these subsystems needs to be modelled with an appropriate level of details, so as to obtain a numerical model which is sensitive to the operating conditions (driving cycle and external temperature) and to give the output of interest: energy consumption, vehicle performance, and temperature in the cabin. The next sections elaborate on the level of physical assumptions used for each subsystem required by the analysis.

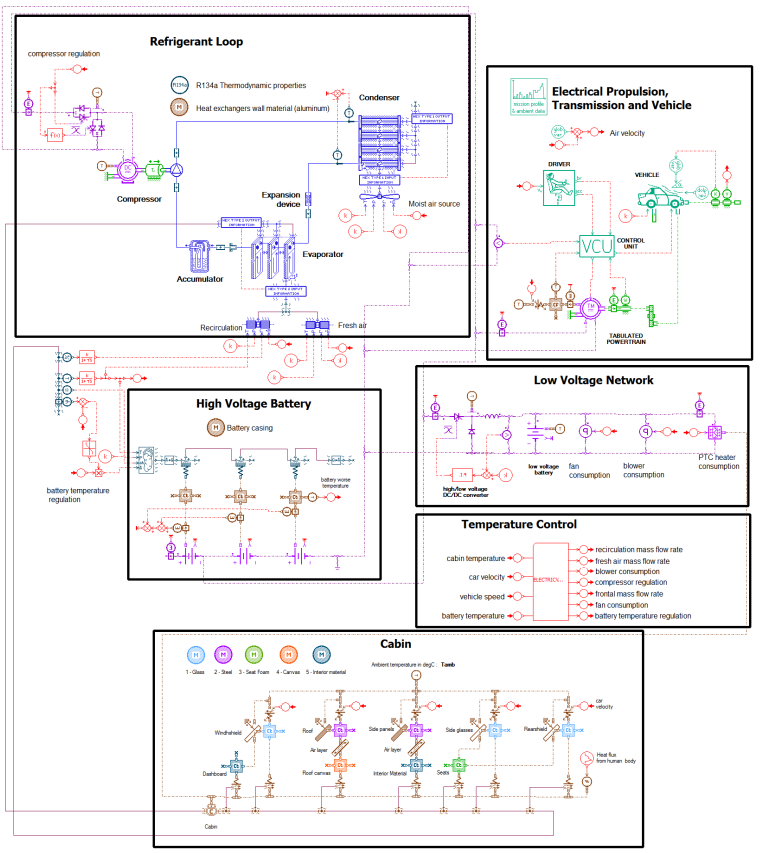

Figure 1: Simulation model of the complete EV

\section{Battery model}

The battery to be modelled is a Lithium-ion technology, consisting in 114 modules for a total capacity of $36 \mathrm{kWh}$ and a maximum voltage of $480 \mathrm{~V}$. The battery is cooled-down and heated-up by the air coming from the cabin.

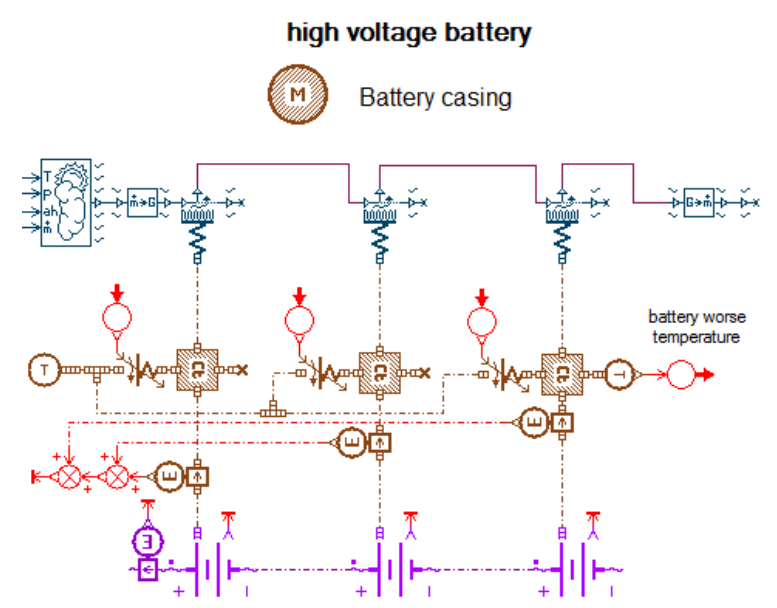

Figure 2: Model of the high voltage battery

The developed model consists in a functional model represented by an equivalent electric circuit which includes a variable voltage source (also known as open circuit voltage) and a variable resistance (also known as internal resistance), both 
values being function of the state of charge (SOC) and the battery temperature.

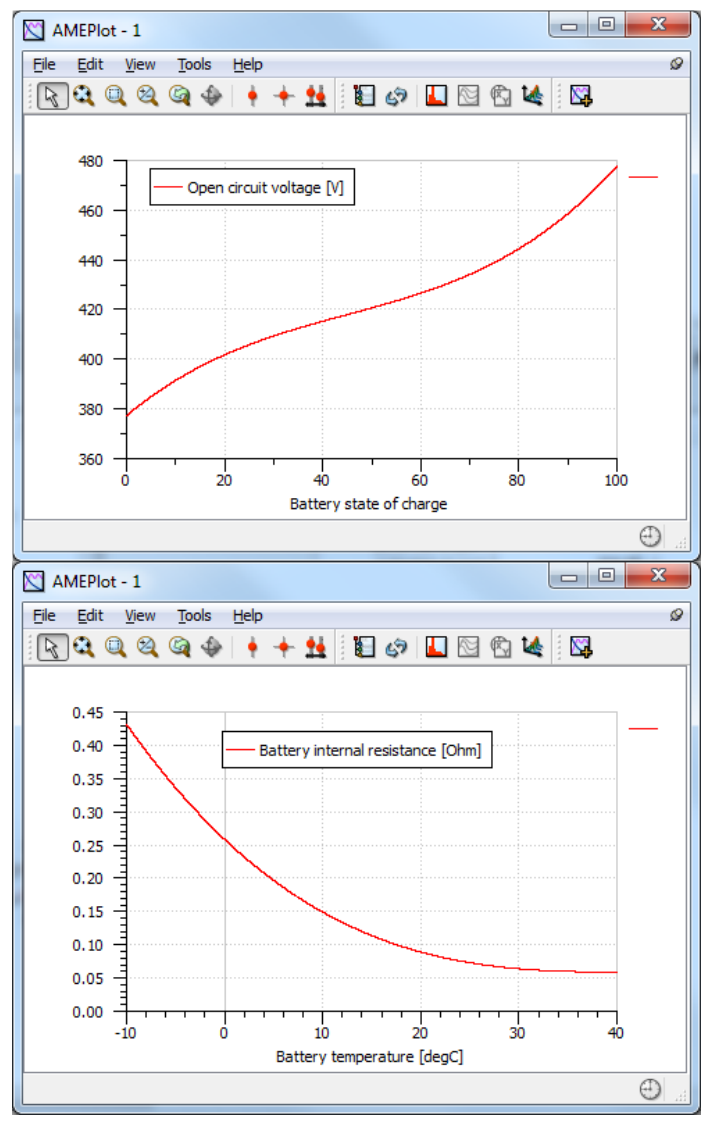

Figure 3: battery OCV and internal resistance

The electric model computes the battery output voltage, state of charge and Joule effect losses.

A more advanced model could be used to simulate the physical phenomena inside the battery, is presented in [5] and [6]. Thus, the open circuit voltage, the ohmic losses, the transfer of charge, the double layer capacitance and the diffusion of species can be represented. This approach allows being more accurate in the dynamic voltage response and includes a parameterization assistant tool.

As the battery performance depends on its temperature, a thermal model needs to be developed. The thermal capacity of the battery is represented as well as the thermal exchanges between moist air and a finned wall in which the cells are encapsulated. A regulation is setup in order to maintain the battery temperature at around $35^{\circ} \mathrm{C}$. For this, part of the air coming from the cabin is used for cool-down when the battery reaches $35^{\circ} \mathrm{C}$ or for heat-up when the battery temperature is lower than the cabin temperature.

\section{Electric machine}

For performance and energy consumption analyses, an average model (Figure 4) of an electric powertrain is sufficient. The electric machine efficiency characterization is based on data as a function of rotary speed, voltage and temperature.

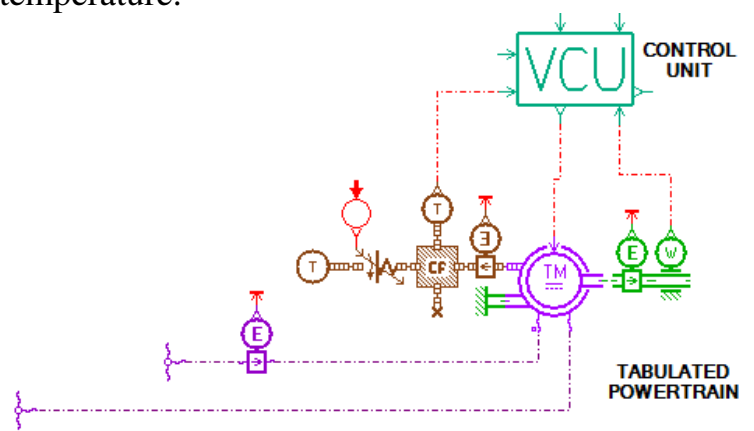

Figure 4: Model of the electric powertrain

These tables (Figure 5) are generated starting from a detailled physical model of the electric powertrain including: the electric machine (brushless permanent magnet motor), the 3-phase inverter and the motor torque vector control. This detailed model enables to computes the machine electrical losses (due to joule effects in the stator windings) and mechanical losses (due to rotor frictions) as well as the inverter losses (due to the semiconductors conduction and switching losses). The look-up table based model is suited to simulate long cycles with high level of accuracy while keeping reasonable CPU times.

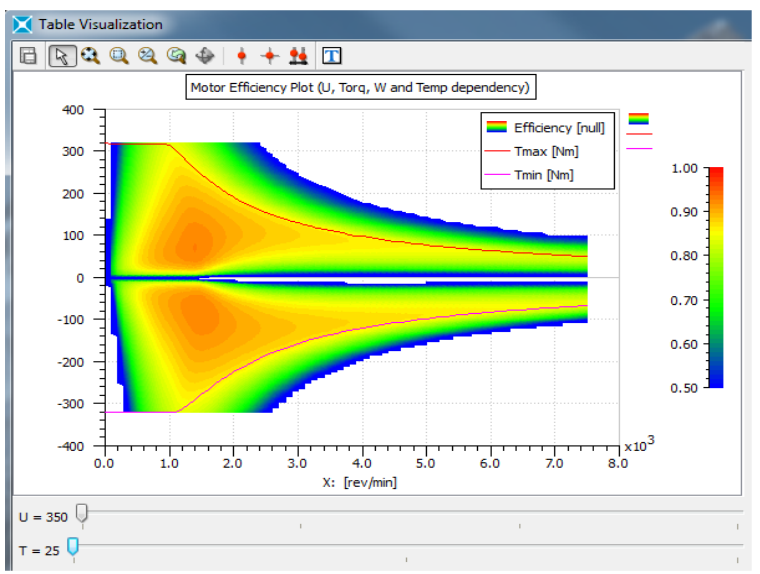

Figure 5: Machine efficiency function of rotary speed, voltage and temperature 


\section{The driveline and the vehicle}

The model of the vehicle (Figure 6) is suited for longitudinal displacement only, and it is described with the following parameters:

- Mass: 1.4 tons (batteries included)

- Cx: 0.3, vehicle area: $2 \mathrm{~m} 2$

- Tire: 165/65/R15

- Gear ratio between machine and wheel: 5

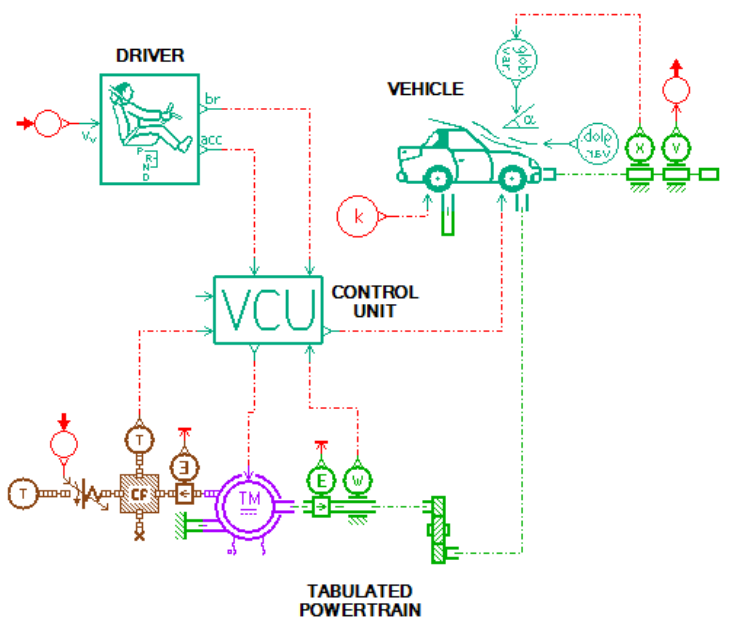

Figure 6: Model of the vehicle connected to the electric powertrain

The driver model computes the acceleration pedal and braking pedal signals in order to match the driving cycle profile. The control unit translates the acceleration command into a motor torque command, and splits the braking command into a regenerative braking generator torque command and a mechanical braking command.

\section{The air-conditioning system}

A "physical simulation" methodology, meaning a set of virtual components like ducts, expansion valves, receivers, accumulators, condensers, evaporators or compressors, which can be interconnected to virtually design an AC loop under the multi-domain system simulation platform LMS Imagine.Lab AMESim, has been described in [7].

The system considered (Figure 7) uses R134a refrigerant with an electrically driven compressor (maximum displacement: $75 \mathrm{cc}$ ), which velocity is controlled by a DC machine in order to ensure sufficient cabin cool down.

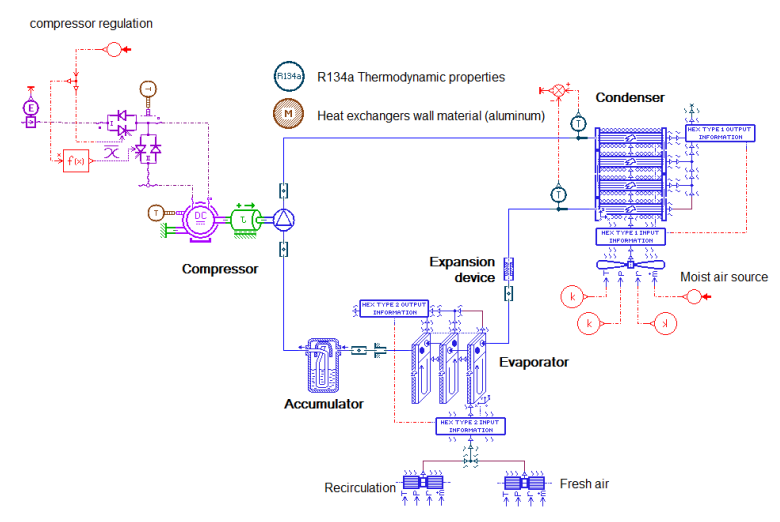

Figure 7: Model of the air-conditioning system

\section{The cabin heating system}

The PTC heater (Positive Temperature Coefficient) is an electric device that heats up the air before flowing into the cabin (electric resistance within which heat is dissipated from Joule effect losses and is used to heat-up air that is flowed through the device). In the considered vehicle, the PTC is plugged on the low voltage electric network (Figure 8) and is composed of 3 stages of $600 \mathrm{~W}$ each. A regulation activates 1, 2, or 3 heater-stages so as to reach the required cabin temperature.

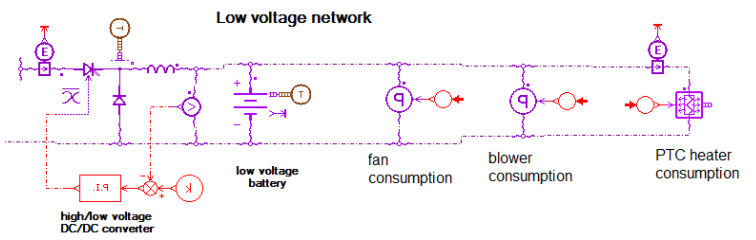

Figure 8: Model of the low voltage network including PTC heaters

Other electric consumers are connected to the low voltage network:

- the fan, located in front of the refrigerant loop condenser,

- the blower which circulates air in the HVAC system and in the cabin.

These consumers are based on functional energetic models, with a limited set of parameters, following the methodology presented in [8]. Losses due to the semiconductors conduction and switching losses are also taken into account into the DC/DC converter. 


\section{The cabin thermal balance model}

The purpose of the cabin model is to determine the air temperature and humidity evolution taking into account the car velocity profile, the solar loads and the heat exchange between the panel and the air within cabin. In this particular case, the objective is to get the evolution of the temperature in the cabin for different car speeds (might they also be zero).

To model the cabin, the principle is to use elementary physical blocks like thermal masses, forced convection, moist air source and volume, radiation... and connect them together in order to represent the final complete cabin subsystem. A simplified example is shown on Figure 9.

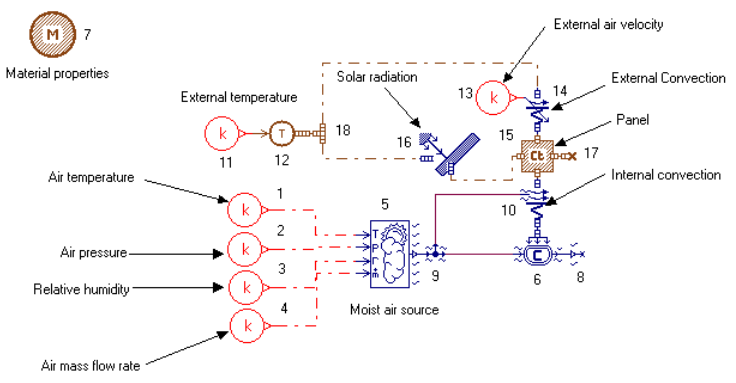

Figure 9: Simplified cabin model which contains a volume, a source of moist air, the external exchange and the solar loads

For the present study, we only considered a single moist air volume for the cabin which thermally interacts with the surfaces shown in Figure. For each surface (Figures 10 and 11), internal and external heat transfers with internal and external air are represented.

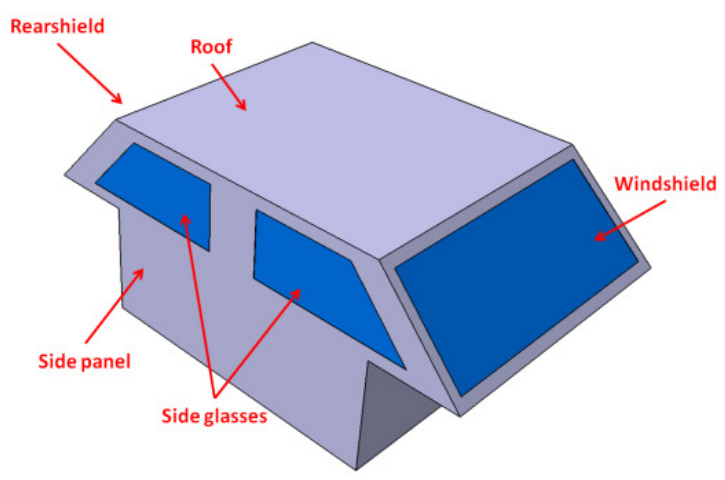

Figure 10: External surfaces

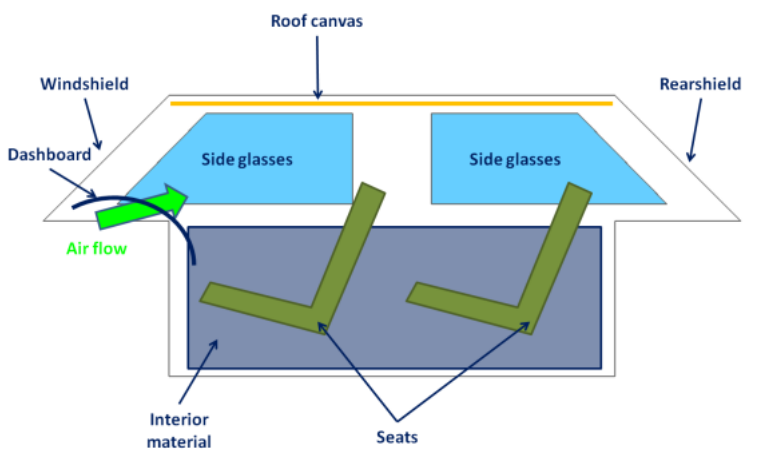

Figure 11: Internal Surfaces

Solar loads are applied on the external surfaces:

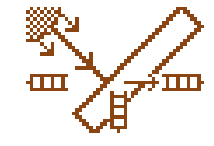
surface: part of the solar power is absorbed by the surface, part of the solar power is transmitted and part of the solar power is reflected to the ambient. In this case, the transmitted power heats up the components inside the cabin (dashboard and seats for example).

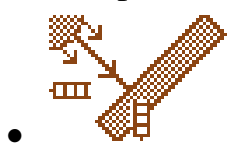

Solar radiation on opaque surface: part of the solar power is absorbed by the opaque surface, and the other part of the solar power is reflected.

The heat exchanges with the external and internal surfaces are computed as follows:

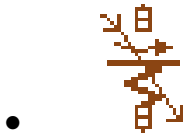

Free and forced convection, external surface: mixed external convection between a wall and its surrounding (ambient air) at variable temperature and variable fluid velocity. In this case, we have considered the vehicle velocity for all the external surfaces (windshield, rear shield, side glasses, side panels and roof).

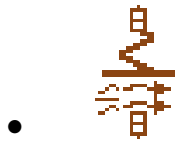

Free and forced convection, internal surface: mixed internal convection between a wall and an internal environmental moist air (cabin) at variable temperature and variable fluid mass flow rate. The environmental moist air velocity $\mathrm{V}$ in $\mathrm{m} / \mathrm{s}$ is computed using the moist air density at the 
considered temperature and the crosssectional area of the flow. An aerodynamic coefficient is used as a gain value to calibrate the internal air velocity and match CFD calculation results.

To model the panel layers (roof and side panels, Figure 12), 2 thermal capacities and a thermal resistance in between were considered. The thermal resistance is modelled using an air layer.

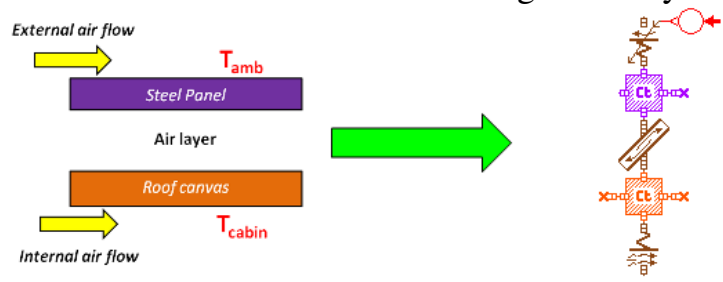

Figure 12: Roof layers and associated model

Finally, the model (Figure 13) includes a single moist air volume for the whole cabin. This volume receives the moist air flow coming from the HVAC system. The HVAC controls the cabin air recirculation in order to accelerate both the warm-up and the cool down, and the mixing of fresh air with recirculate air

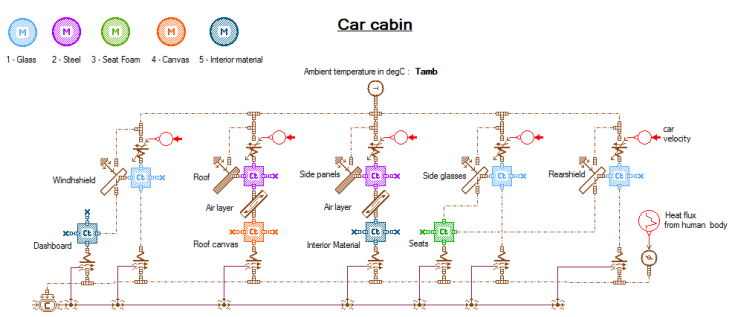

Figure 13: Model of the cabin thermal balance

\section{The driving cycle and external conditions scenario}

The driving cycle considered is US06 Supplemental Federal Test Procedure (SFTP). It was developed to address the shortcomings with the FTP-75 test cycle in the representation of aggressive, high speed and/or high acceleration driving behaviour, rapid speed fluctuations, and driving behaviour following start-up. The duration of the cycle is 600 seconds (Figure 14).

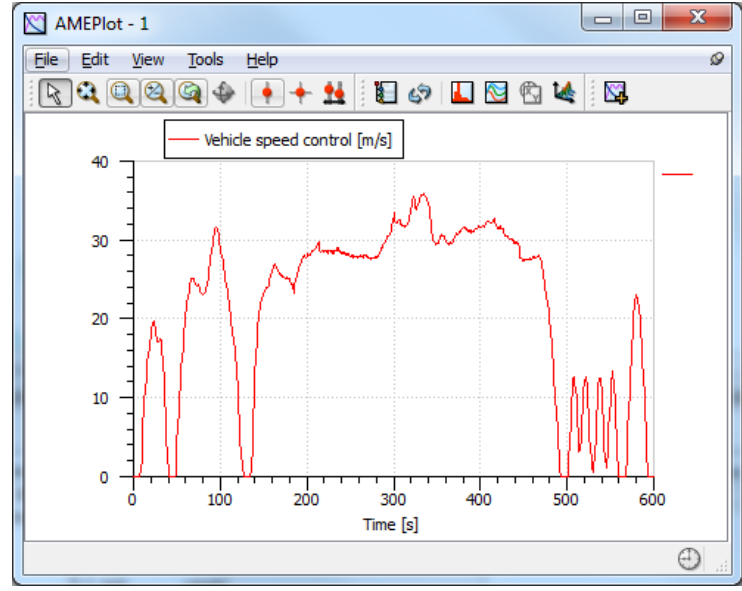

Figure 14: SFTP-US06 driving cycle

The driving cycle is going to be simulated for the different following scenarios:

\begin{tabular}{|c|c|c|c|c|c|}
\hline 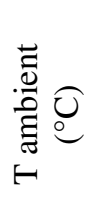 & 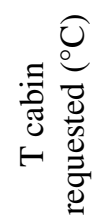 & 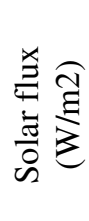 & 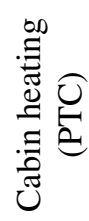 & 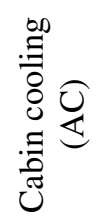 & 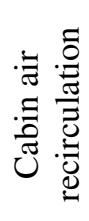 \\
\hline-5 & 20 & 0 & ON & OFF & $\mathrm{ON}$ \\
\hline 0 & 20 & 0 & ON & OFF & ON \\
\hline 5 & 20 & 100 & ON & OFF & $\mathrm{ON}$ \\
\hline 10 & 20 & 200 & ON & OFF & ON \\
\hline 15 & 20 & 400 & ON & OFF & $\mathrm{ON}$ \\
\hline 20 & 20 & 600 & OFF & OFF & OFF \\
\hline 25 & 20 & 700 & OFF & ON & ON \\
\hline 30 & 20 & 850 & OFF & ON & $\mathrm{ON}$ \\
\hline 35 & 20 & 1000 & OFF & ON & $\mathrm{ON}$ \\
\hline
\end{tabular}

\section{Simulation results and analysis}

The graphs show the transient results for both cabin temperature (Figure 15) and battery state of charge (Figure 16), for each operating conditions. One can notice that for certain external conditions $\left(-5^{\circ} \mathrm{C}\right.$ and $\left.0^{\circ} \mathrm{C}\right)$, the heating system is not sufficient to reach the temperature target. Cabin temperature oscillations occur at various ambient temperatures $\left(5^{\circ}, 10^{\circ} \mathrm{C}\right.$ and $15^{\circ} \mathrm{C}$ ): they correspond to the activation and de-activation of various stages of the PTC. 


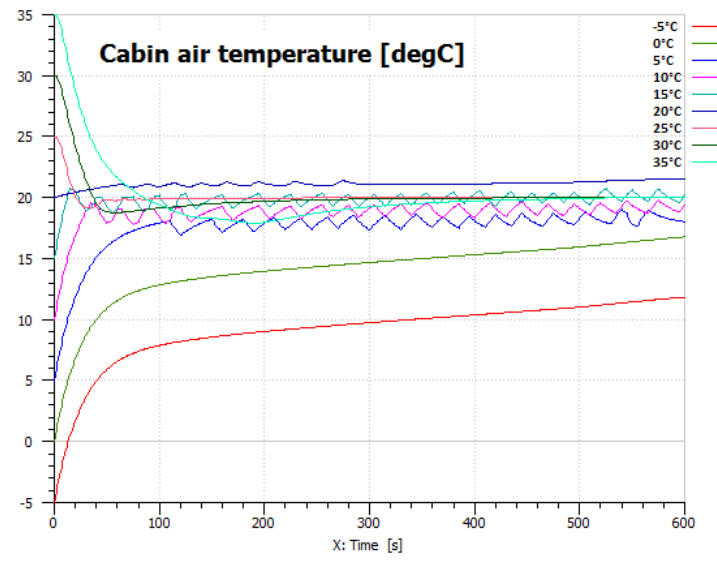

Figure 15: cabin temperature for various ambient temperatures

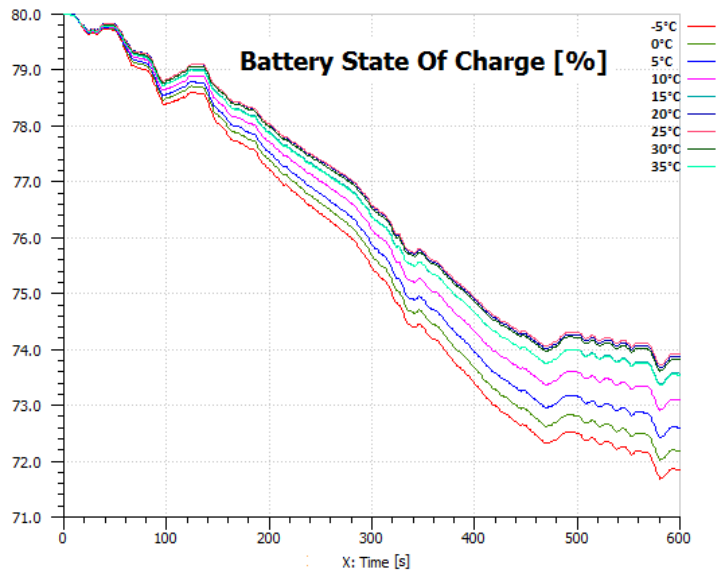

Figure 16: battery state of charge for various ambient temperatures

The model also computes the instantaneous power consumption and the energy transfer within the various components of the vehicle during the complete cycle. The graph Figure 17 details the energy consumption for each component. It is clear that the electrical propulsion is the main consumer of the Electric Vehicle, with losses which are mostly independent on the temperature conditions.

Battery losses are on the contrary highly dependent on temperature: at low temperature ($5^{\circ} \mathrm{C}$ ), the battery losses are important. It can be interesting then to simulate various technologies of battery heating systems in order to understand the cost and the benefits in term of energy consumptions.

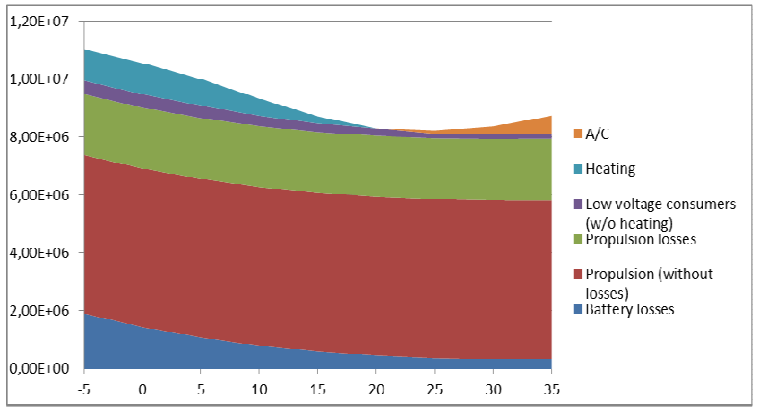

Figure 17: battery energy consumption $[\mathrm{J}]$ function of the ambient temperature $[\operatorname{deg} C]$

Considering the energy consumed by the thermal comfort devices, it is more expensive in term of energy to warm-up the cabin than to cool it down (Figure 18). This is due to the efficiency of each device, close to $100 \%$ for PTC heaters but a Coefficient of Performance of 2.2 in the case of the simulated AC system.

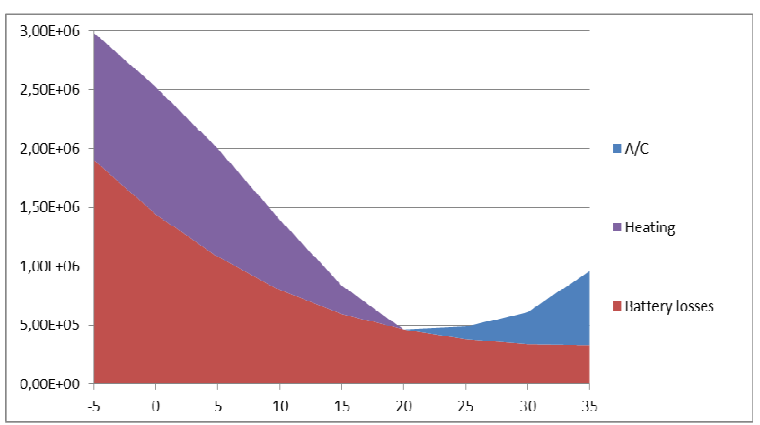

Figure 18: A/C consumption [J], PTC heater consumption $[\mathrm{J}]$ and battery losses $[\mathrm{J}]$ function of the ambient temperature $[\mathrm{degC}]$

Finally, the graph presented in Figure 19 highlights the classical trend in the energy consumption increase at low and high ambient temperature, with a minimum value around $20^{\circ} \mathrm{C}-25^{\circ} \mathrm{C}$.

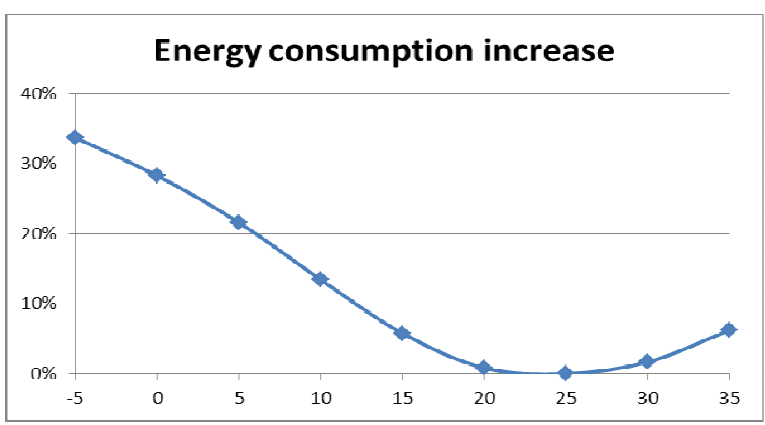

Figure 19: Vehicle energy consumption increase function of the ambient temperature [degC] 


\section{Conclusion}

The numerical model presented in this paper allows estimating the energy consumption of an Electrical Vehicle, as well as the cabin temperature. The split between the energy requested by the propulsion and the passenger thermal comfort devices (R134a refrigerant loop and PTC heaters) is presented, as well as an estimation of the losses into the main electrical components: battery and propulsion.

This numerical model can be used to quickly assed the following scenarios, some of them implying some architectural changes of the model:

- simulate other drive cycles (European, Japanese, USA or custom)

- simulate other refrigerants: $1234 \mathrm{yf}, \mathrm{CO} 2 \ldots$

- simulate other cooling and heating technologies such as heat pumps

- simulate the impact of cabin insulation, positive in term of cabin temperature but negative in term of weight increase for example.

\section{References}

[1] H. Kobayashi, K. Yamada, Multi-Physics System Simulation for Vehicle energy Management Optimization, ATA 3rd European Workshop Mobile air conditioning, Vehicle thermal Systems and Auxiliaries, 26-27 nov 2009, Italy

[2] A. Taklanti, Use of system simulation to evaluate the impact of additional heating strategies on vehicle fuel consumption and pollutant emissions, EAEC2007 - 11th European Automotive Congress "Automobile for the Future", 30 May - 1 June 2007, Budapest, Hungary

[3] H. Dupont, Dr. H.-J. Nuglisch, M. Lankes, Complete vehicle model to optimize mild hybrid and thermal, strategies and to predict $\mathrm{CO} 2$ emissions: development, validation and analyses, AEA 2008 - 4th European Conference on Alternative Energies for the Automotive Industry

[4] M. Brunelli, M. Silvestri, N. Sabatier, Future trends and virtual Vehicle Energy Management of hybrid architectures, 8th International Conference - Powertrain technologies for $\mathrm{CO} 2$ reduction, 17-18 November 2010, Italy
[5] J. Hafsaoui, J. Scordia, F. Sellier, W. Liu, C. Delacourt, P. Aubret, Development of an electrochemical battery model and its parameters identification tool, JSAE paper 20105152

[6] J. Hafsaoui, F. Sellier, Electrochemical model and its parameters identification tool for the follow up of batteries ageing, EVS-25 Shenzhen, China, Nov. 5-9, 2010, The 25th World Battery, Hybrid and Fuel Cell Electric Vehicle Symposium \& Exhibition

[7] A. El Bakkali, A Virtual Air Conditioning System Based on the Physical Simulation of AC Components, FISITA 2004 World Automotive Congress, 23-27 May, Barcelona, Spain

[8] N. Kieny, E. Laurain, I. Mohand-Kaci, Automotive boardnet design and analysis through multi-level multi-domain system simulation, EVS-25 Shenzhen, China, Nov. 59, 2010, The 25th World Battery, Hybrid and Fuel Cell Electric Vehicle Symposium \& Exhibition

\section{Authors}

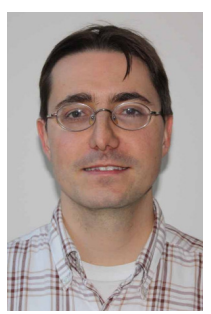

Ing. Lionel Broglia Patron

LMS Imagine, 84 quai Charles de Gaulle 69006 Lyon, Tel: +33 437697237

Email: lionel.broglia@1msintl.com Graduated from Université Claude Bernard of Lyon (France), 10+ years involvement in multi-domain system simulation, now Product Manager for Thermofluids and Electrical solutions, mainly in automotive and other ground vehicles industries.

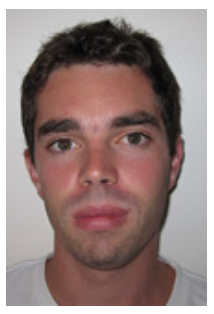

Ing. Gabriel Autefage

LMS Imagine, 84 quai Charles de Gaulle 69006 Lyon, Tel: +33437697921

Email: gabriel.autefage@1msintl.com Graduated from Ecole d'Ingénieur en Génie des Systèmes Industriels of $\mathrm{La}$ Rochelle (France), joined LMS Imagine in 2009 as Electromechanical Product Developer.

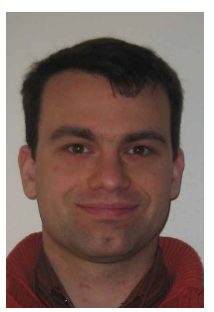

Dr. Matthieu Ponchant

LMS Imagine, 84 quai Charles de Gaulle 69006 Lyon, Tel: +33 437697269

Email: matthieu.ponchant@1msintl.com Graduated from Ecole Nationale Supérieure de Mécanique et d'Aérothechnique of Poitiers (France), worked for 3 years in Engine Cooling system at VALEO before joining LMS Imagine in 2009 as Thermal Management Product Developer. 